\title{
Moderate-to-Vigorous Physical Activity in Primary School Children: Inactive Lessons Are Dominated by Maths and English
}

\author{
Andy Daly-Smith ${ }^{1,2,3,4, *}$, Matthew Hobbs ${ }^{5}{ }^{\mathbb{D}}$, Jade L. Morris ${ }^{6}$, Margaret A. Defeyter ${ }^{7} \mathbb{D}$, Geir K. Resaland $^{3}$ and \\ Jim McKenna ${ }^{4}$ D
}

Citation: Daly-Smith, A.; Hobbs, M.; Morris, J.L.; Defeyter, M.A.; Resaland G.K.; McKenna, J. Moderate-to-

Vigorous Physical Activity in Primary School Children: Inactive Lessons Are Dominated by Maths and English. Int J. Environ. Res. Public Health 2021, 18, 990. https://doi.org/10.3390/ijerph 18030990

\section{Academic Editors:}

Cristina Cadenas-Sanchez,

Pontus Henriksson and

Idoia Labayen

Received: 16 December 2020

Accepted: 19 January 2021

Published: 22 January 2021

Publisher's Note: MDPI stays neutral with regard to jurisdictional claims in published maps and institutional affiliations.

Copyright: (c) 2021 by the authors Licensee MDPI, Basel, Switzerland. This article is an open access article distributed under the terms and conditions of the Creative Commons Attribution (CC BY) license (https:// creativecommons.org/licenses/by/ $4.0 /)$.
1 Faculty of Health Studies, University of Bradford, Bradford, West Yorkshire BD7 1DP, UK

2 Centre for Applied Education Research, Wolfson Centre for Applied Health Research, Bradford Royal Infirmary, West Yorkshire BD9 6TP, UK

3 Center for Physically Active Learning, Faculty of Education, Arts and Sports, Western Norway University of Applied Sciences, 6856 Sogndal, Norway; geir.kare.resaland@hvl.no

4 School of Sport, Carnegie, Leeds Beckett University, Leeds LS6 3QT, UK; j.mckenna@leedsbeckett.ac.uk

5 School of Health Sciences, College of Education, Health and Human Development, University of Canterbury, Christchurch, Canterbury 8041, New Zealand; matt.hobbs@canterbury.ac.nz

6 Centre for Society and Mental Health, Department of Health Service and Population Research, Institute of Psychiatry, Psychology \& Neuroscience, King's College London, London WC2B 6LE, UK; jade.morris@kcl.ac.uk

7 Healthy Living Lab, Faculty of Health \& Life Sciences, Northumbria University, Newcastle upon Tyne NE 7 7XA, UK; greta.defeyter@northumbria.ac.uk

* Correspondence: a.daly-smith@bradford.ac.uk

Abstract: Background: A large majority of primary school pupils fail to achieve 30-min of daily, in-school moderate-to-vigorous physical activity (MVPA). The aim of this study was to investigate MVPA accumulation and subject frequency during academic lesson segments and the broader segmented school day. Methods: 122 children ( $42.6 \%$ boys; $9.9 \pm 0.3$ years) from six primary schools in North East England, wore uniaxial accelerometers for eight consecutive days. Subject frequency was assessed by teacher diaries. Multilevel models (children nested within schools) examined significant predictors of MVPA across each school-day segment (lesson one, break, lesson two, lunch, lesson three). Results: Pupils averaged $18.33 \pm 8.34 \mathrm{~min}$ of in-school MVPA, and 90.2\% failed to achieve the in-school 30-min MVPA threshold. Across all school-day segments, MVPA accumulation was typically influenced at the individual level. Lessons one and two-dominated by maths and English-were less active than lesson three. Break and lunch were the most active segments. Conclusion: This study breaks new ground, revealing that MVPA accumulation and subject frequency varies greatly during different academic lessons. Morning lessons were dominated by the inactive delivery of maths and English, whereas afternoon lessons involved a greater array of subject delivery that resulted in marginally higher levels of MVPA.

Keywords: academic lessons; moderate-to-vigorous physical activity; whole-school; physical activity; physically active learning

\section{Introduction}

Globally, half of all children do not achieve the recommended threshold of $60 \mathrm{~min}$ of daily moderate-to-vigorous physical activity (MVPA), this rises to between $70 \%$ and $76 \%$ in European countries [1-4]. Moreover, levels of MVPA decline by approximately $4.2 \%$ per year from the age of seven [4-6], when formalised teaching commences in many westernised countries. To reverse this decline, effective physical activity interventions are required during childhood school years. Whole-school approaches to physical activity [7] are recommended in global [8,9] and country-specific policies [10]. However, meta-analyses 
reveal that the current approaches have little, if any, effect on total daily MVPA [11,12]. The recently developed Creating Active Schools Framework perhaps shines a light on why such failures occur, as many previous interventions have failed to address the multiple factors required to operationalise a whole-school physical activity approach [7]. It is essential that whole-school interventions take a behaviour change approach to address policy, mobilise stakeholders, create effective social and physical environments and implement physical activity across the seven available opportunities [7].

The majority of children attend school for six to seven hours per weekday, giving ample opportunity for intervention [13]. Highlighting the potential of schools, many national policies, including those of the United Kingdom (UK), recommend that schools provide all children with a minimum of 30-min in-school MVPA per day [10]. A recent systematic review [14] and meta-analysis [15] showed that in-school MVPA ranged between 16 and $61 \mathrm{~min}$. However, 90\% of children failed to achieve the 30-min MVPA threshold [14]. Such low levels of MVPA during school hours is likely to have a negative impact on pupils' physical and mental wellbeing $[16,17]$. Of equal, if not greater, importance to the education system, inactive school environments could undermine academic performance [18]. Yet, while positive associations are being observed between academic performance and physical activity [19], interventions within-schools have failed to demonstrate benefits in any subject other than maths [20]. Such shortcomings might be attributed to the failure of programs to address the many factors required for the effective implementation and poor sustainability of current interventions [7].

Enhancing the intervention design requires a detailed understanding of MVPA accumulation during the school-day. Discretionary physical activity occurs= where children have control of their choices, such as break (recess) [21]. In compulsory segments, i.e., academic lessons, the activity is directed by others. The physical activity profiles of discretionary and compulsory segments have been highlighted in previous research [22-26], identifying break/lunchtime and Physical Education (PE) lessons as the most active in-school periods. Inactive and sedentary academic lessons often dominate the school day [13], meaning they offer an additional avenue for increasing in-school physical activity beyond the traditional focus on break [27] and Physical Education [28]. Five systematic reviews [29-31], two including a meta-analysis [32,33] support focusing on integrating more movement within curricular lessons, highlighting the potential of physically active learning (PAL) and classroom movement breaks (CMB) for increasing the levels of MVPA.

Increasing the effectiveness and implementation of PAL and CMB interventions requires a greater understanding of MVPA accumulation within academic lesson segments. While a growing evidence base exists for the school-level effects on MVPA during PE, break and lunch, limited understanding exists for academic lessons [23,26]. Compounding the issue, current segmented-day research combines all academic lessons into one homogenous segment. This approach likely masks that different lesson segments have varying physical activity profiles and underlying lesson constructs [25].

As lessons are based on different subjects, such as maths or PE, with differing physical activity profiles [34], they should be assessed as their own entity, not together. Such refinements in the current thinking would support intervention developers to target the most inactive lessons. In addition, understanding the delivery frequency of the different subjects with which movement could be integrated could promote further MVPA across the school day. The primary aim of the study is to investigate the impact of different lesson segments on MVPA accumulation in primary school children. A secondary objective is to identify the frequency and distribution of the different National Curriculum subjects across the different lesson segments.

\section{Materials and Methods}

\subsection{Participants}

The current study uses baseline data from the participants who took part in the Redcar and Cleveland physical active learning project [35]. Participants were recruited 
from Year Five (aged 9 to 10 years) classes across six primary schools in the North East of England. School Games Organisers approached the selected schools, forming a convenience sample. The proportion of children receiving free school meals across schools ranged from $31.8 \%$ for the most deprived to $2.4 \%$ for the least deprived $(M=16.4 \%)$. Institutional approval was received from Leeds Beckett Research Ethics Committee (reference: 37482). Following headteacher consent, parents and pupils were sent information letters to their home address via the school. All participants who provided consent and assent were included in the study.

\subsection{Protocol}

Data collection took place in January, winter in England. Two schools were visited per day over three consecutive days. During the visit, pupils were provided with accelerometers and had their height (meters) and body mass $(\mathrm{kg})$ measured. While accelerometers were being distributed, the lead researcher encouraged pupils to identify strategies to increase wear-time, e.g., "placing it next to my toothbrush". Following the accelerometer briefing, the lead researcher explained the class-level activity diary to the teacher.

\subsection{Physical Activity Assessment}

Physical activity levels were measured objectively, using a combination of GT1M and GT3X accelerometers (ActiGraph, Pensacola, FL, USA). While it is preferable to use the same accelerometer model, previous research has demonstrated the high level of compatibility of these two monitors in standardised and free-living activities [36,37]. Monitors were worn on the right hip, in alignment with previous school-based studies in children [25]. Participants were required to wear the monitors for eight consecutive days, (i) every day, (ii) throughout the day, except for sleeping and water-based activities, and (iii) to continue wearing the monitor, even if a day was missed. Monitors were set to record from 12 a.m. on day two, producing seven days of data collection while allowing for a minimum of a 12-h induction [38]. Data were collected in 15-s epochs. The epoch length was chosen alongside the selected cut-points. Utilising an epoch that differs from those validated in conjunction with the cut-points can lead to inaccurate outcomes [39,40]. Evenson [41] cut-points were used to determine time spent in sedentary time $\left(0-25\right.$ counts $\left.15^{-1}\right)$, light physical activity ( $26-573$ counts $\left.15^{-1}\right)$ and MVPA $\left(\geq 574\right.$ counts $\left.15^{-1}\right)$.

Accelerometer data were downloaded using Actilife (version six, Pensacola, FL, USA) and then converted into AGD files prior to being analysed in Kinesoft (v3.3.75, Kinesoft, Loughborough, UK). Non-wear time was identified by a period of $\geq 60 \mathrm{~min}$ of zeros allowing for a period of $2 \mathrm{~min}$ non-wear time [5], with the total duration of these blocks representing non-wear time. Spurious values were identified as $\geq 30,000$ counts. Validwear criteria were set at $\geq 3$ school days [42,43] with a wear time $\geq 480$ min per day. While $480 \mathrm{~min}$ is at the lower end of the wear criteria and may underestimate total daily MVPA levels [42], a significant proportion of school-based studies in children have utilised this threshold. Due to the focus on in-school physical activity, a longer wear-time was not deemed necessary for the current study. To confirm in-school wear-time for valid days, a further visual check of each accelerometer profile was undertaken. For segmented day analysis, independent segments were removed if $<100 \%$ wear time was identified through visual screening.

\subsection{Teacher Diaries}

In-school segments were characterised using teacher diaries. Specific segments were extracted from the pupils' accelerometer profiles using the windows function in Kinesoft. Teachers were requested to complete the diary immediately after each segment, noting timings for the start and end of the school day, lessons one, two and three, breaks and lunchtimes. In addition, teachers were requested to record different subjects that occurred within each lesson period [26]. The following segments were identified for all schools:

- In-school; the beginning of the first lesson to the end of the last lesson; 
- Lesson one: start of school to the beginning of the first break (recess);

- Break: end of lesson one to the beginning of lesson two;

- Lesson two: end of the break until the beginning of lunchtime;

- Lunchtime: end of lesson two to the beginning of lesson three, includes time for eating;

- Lesson three: end of lunchtime until the end of school;

- Lesson time: total lesson time (lesson one + lesson two + lesson three).

\subsection{Identifying Lesson Type Frequency}

Lesson frequency was the number of times a subject appeared within each of the different lesson segments (lesson one, lesson two, lesson three). These were totaled across schools. Teacher diaries established the day and the frequency with which the different subjects (maths, geography, English, history, science, languages, computing, music, art and design, PE, Personal, Social, Health and Economic education (PSHE) and design and technology) occurred in each lesson segment. These were coded in alignment with the Key Stage Two National Curriculum for England [44]. After a visual check of the teacher diaries, two additional lesson types were identified, as they occurred in two or more schools: assembly-a gathering of part or whole school for a special programme or communication of information; golden time-free time for pupils to self-select activity which was often used as a reward for hard work.

\subsection{Anthropometry}

Height: Secca 213 floor standing height measure (Seca Deutschland, Hamburg, Germany) and body mass: Secca 877 (Seca Deutschland, Hamburg, Germany) were measured in alignment with the "Assessing the Levels of Physical Activity and Fitness "ALPHA fitness testing battery protocol [45]. Prior to measurement, participants were asked to move jumpers and shoes, completing the measurements in trousers or a dress and a shirt. Body Mass Index (BMI) was calculated using weight $(\mathrm{kg}) /$ height $^{2}(\mathrm{~m})$. The British growth reference chart values were used to convert BMI into standard deviation scores (BMI z-score) while accounting for normal growth by age and gender [46]. Using BMI z-scores, children were classified as normal weight $(<85$ th centile, BMI z-score $<1.04)$, overweight (85th to 95th centile, BMI z-score 1.04-1.639) and obese (95th centile, BMI z-score $>1.64$ ). Biological maturity (maturity offset) was established using children's age from peak height velocity (APHV) [47]. Due to not capturing sitting height, the standing height simplified equation was used for both boys and girls [47].

\subsection{Data Analysis}

Individual and school-level descriptive characteristics are presented as Mean \pm Standard Deviation $(S D)$ for all measured variables. Normal distribution was confirmed for all variables using the Kolmogorov-Smirnov test $(p>0.05)$. One-way ANOVA (Tukey post hoc) assessed differences between schools in baseline characteristics (i.e., age) and levels of MVPA across the whole day, in-school and all school segments $(p<0.05, p<0.01, p<0.001$, $p<0.0005)$.

Separate multi-level models (unstandardised coefficients $(b)$ ) identified the intraclass correlations (ICC) and significant predictors of the MVPA across each independent segment (lesson, break, lunch, lesson one, lesson two, lesson three). Intraclass correlations identify "the proportion of the total variability that is attributable to the level two unit" [48]. Multilevel models account for the clustering of pupils within schools. Independent models were constructed with random intercepts for MVPA, across the different segments of the school day. Progression to random slopes resulted in output errors. Models were built using the recommended three-stage process [49]. First, only the level-two clusters (the schools) and outcome. Second, the level-one predictors were added and third, school-level predictors were added. All predictors were identified a priori through the previous literature and have been shown to affect the amount of time spent within each activity threshold during key segments of the school day [50]. School-level predictors included the percentage of pupils 
receiving free school means (FSM) and segment length. Pupil-level predictors included gender, maturity offset and BMI z-score. The significance of the changes in the models were assessed using $-2 \log$-likelihood with significance accepted $(p<0.05)$. Residuals were normally distributed, and all analyses were conducted in IBM SPSS 21 (IBM, Armonk, NY, USA).

\section{Results}

\subsection{Sample Characteristics}

Of the 149 participants ( $M_{\text {age }} 9.91 \pm 0.30$ years), $122(82 \%)$ returned valid accelerometer profiles (Table 1). No significant differences in measures were observed between 27 excluded participants and the final sample of 122 participants. For the final sample $(n=122)$, only height was deemed significantly different between the six schools $\left(F_{(5,121)}=3.90\right.$, $p=0.003$; Table 1) and there was a higher proportion of girls within the sample compared to boys.

Table 1. Participant descriptive characteristics by school (Mean $\pm S D$ unless stated).

\begin{tabular}{|c|c|c|c|c|c|c|c|}
\hline & $\begin{array}{c}\text { Total } \\
(n=122)\end{array}$ & $\begin{array}{l}\text { School } 1 \\
(n=27)\end{array}$ & $\begin{array}{c}\text { School } 2 \\
(n=22)\end{array}$ & $\begin{array}{c}\text { School } 3 \\
(n=18)\end{array}$ & $\begin{array}{c}\text { School } 4 \\
(n=21)\end{array}$ & $\begin{array}{c}\text { School } 5 \\
(n=17)\end{array}$ & $\begin{array}{c}\text { School } 6 \\
(n=17)\end{array}$ \\
\hline FSM (\%) & 15.8 & 2.4 & 15.4 & 24.1 & 31.8 & 14.36 & 10.2 \\
\hline \multicolumn{8}{|l|}{ Gender (\%) } \\
\hline Boys & 42.6 & 44.4 & 45.5 & 38.9 & 52.4 & 35.3 & 35.3 \\
\hline Girls & 57.4 & 55.6 & 54.5 & 61.1 & 47.6 & 64.7 & 64.7 \\
\hline \multicolumn{8}{|l|}{ Weight Status (\%) } \\
\hline Normal Weight & 63.1 & 51.9 & 77.3 & 66.7 & 52.4 & 82.4 & 52.9 \\
\hline Overweight & 17.2 & 18.5 & 13.6 & 16.7 & 23.8 & 5.9 & 23.5 \\
\hline Obese & 19.7 & 29.6 & 9.1 & 16.7 & 23.8 & 11.8 & 23.5 \\
\hline Age (year) & $9.9 \pm 0.3$ & $10.0 \pm 0.3$ & $9.9 \pm 0.3$ & $9.9 \pm 0.3$ & $10.0 \pm 0.3$ & $9.9 \pm 0.3$ & $10.0 \pm 0.3$ \\
\hline Height $(\mathrm{cm})$ & $140.6 \pm 6.6^{£}$ & $143.8 \pm 5.7^{(5)}$ & $139.1 \pm 6.3$ & $140.7 \pm 7.4$ & $140.6 \pm 6.7$ & $135.9 \pm 4.5$ & $142.4 \pm 6.3$ \\
\hline Body mass (kg) & $37.4 \pm 8.7$ & $40.2 \pm 9.1$ & $35.5 \pm 7.9$ & $37.0 \pm 5.8$ & $38.8 \pm 10.2$ & $32.7 \pm 6.9$ & $38.8 \pm 9.7$ \\
\hline $\operatorname{BMI}\left(\mathrm{kg} / \mathrm{m}^{2}\right)$ & $18.8 \pm 3.4$ & $19.4 \pm 3.9$ & $18.2 \pm 2.9$ & $18.6 \pm 2.3$ & $19.5 \pm 4.1$ & $17.6 \pm 2.6$ & $19.1 \pm 4.1$ \\
\hline BMI z-score & $0.7 \pm 1.1$ & $0.8 \pm 1.3$ & $0.6 \pm 0.9$ & $0.8 \pm 0.8$ & $0.9 \pm 1.3$ & $0.3 \pm 1.0$ & $0.7 \pm 1.2$ \\
\hline Maturity offset (y) & $-2.3 \pm 0.6$ & $-2.2 \pm 0.6$ & $-2.4 \pm 0.6$ & $-2.3 \pm 0.6$ & $-2.4 \pm 0.6$ & $-2.4 \pm 0.6$ & $-2.1 \pm 0.8$ \\
\hline $\begin{array}{l}\text { Accel wear time } \\
\text { (mins) }\end{array}$ & $717.4 \pm 76.4$ & $729.6 \pm 73.9$ & $720.2 \pm 70.7$ & $729.9 \pm 89.4$ & $690.6 \pm 78.6$ & $729.7 \pm 86.8$ & $702.7 \pm 57.1$ \\
\hline
\end{tabular}

FSM: free school meals; BMI: body mass index; BMI z-score: standard deviation scores while accounting for normal growth by age and gender; weight classifications: normal weight $<85$ th centile, overweight 85 th to 95 th centile, obese $>95$ th centile; Significant difference between schools; $£=p<0.001$. Superscript number in brackets ${ }^{(5)}$ identifies a significant difference from another school $(p<0.05)$. For example, in the table above ${ }^{(5)}$ identifies a significant difference between School 1 and School 5.

\subsection{Average Weekday and In-School MVPA Accumulation}

On average, pupils accumulated $44.90 \pm 17.04$ min of MVPA per day. This resulted in $17.2 \%$ of pupils achieving $60 \mathrm{~min}$ of MVPA per day. While this varied greatly between schools (range 38.33 to 49.65$)$ the differences were not significant $\left(\right.$ MVPA $\left(F_{(1,121)}=1.81\right.$, $p=0.116)$. The average duration of time spent in school was $378 \mathrm{~min}$, ranging from 368 to $390 \mathrm{~min}$. Pupils accumulated $18.33 \pm 8.34 \mathrm{~min}$ of MVPA during school hours (school range $12.73 \pm 4.89$ to $22.18 \mathrm{~min}$ ). Overall, $9.8 \%$ of pupils accumulated $>30 \mathrm{~min}$ of in-school MVPA per day, ranging from $0 \%$ to $23.8 \%$ across schools (Figure 1). Across schools, sixty-five percent of pupils accumulated $<20 \mathrm{~min}$ of in-school MVPA each day (range $43 \%$ to $94 \%$ ), and $12.3 \%$ accumulated less than $10 \mathrm{~min}$. 


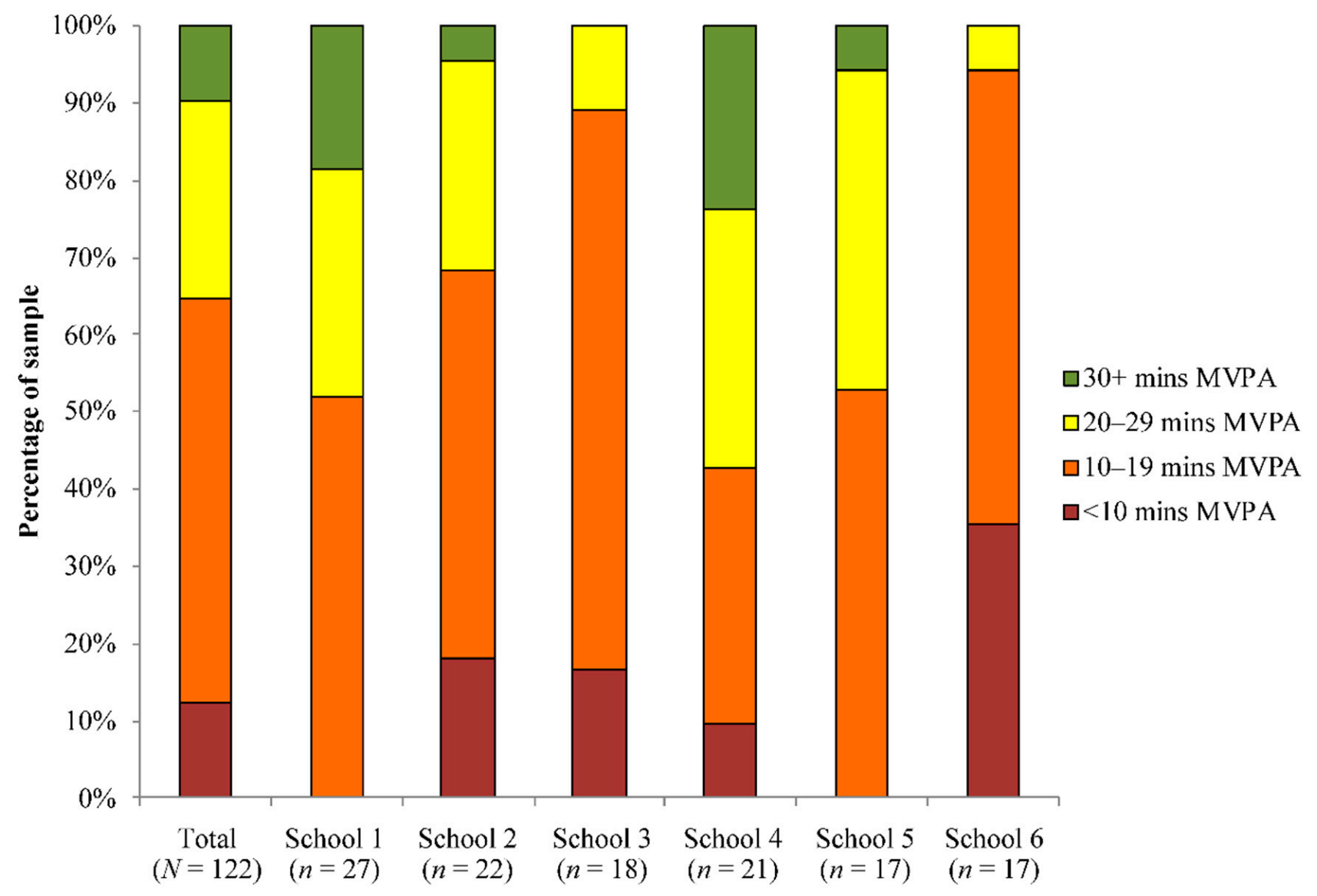

Figure 1. Differences between schools in the proportion of pupils who achieve 0-9 $\mathrm{min}, 10-19 \mathrm{~min}, 20-29 \mathrm{~min}$ and $30+\mathrm{min}$ of in-school moderate-to-vigorous physical activity per day; MVPA—moderate-to-vigorous physical activity.

\subsection{Segmented In-School MVPA Profiles}

Average total lesson duration was $312.5 \mathrm{~min}$ (range 305-325 min), of which, pupils spent $7.81( \pm 4.05) \mathrm{min}$ in MVPA (Table 2$)$. One-way ANOVA and post hoc analyses revealed great variability between schools (3.71 $\mathrm{min}$ to $10.94 \mathrm{~min}\left(F_{(1,121)}=14.72, p<0.0005\right)$. Similarly, during break time (range 15-20 min), pupils accumulated $2.53( \pm 0.24) \mathrm{min}$ of MVPA (15\% in MVPA). One-way ANOVA and post hoc analyses revealed significant variability between schools $\left(F_{(1,121)}=7.38, p<0.0005\right)$. During lunchtimes (range $45-60 \mathrm{~min}$ ), mean MVPA was $8.00( \pm 4.57) \mathrm{min}(16 \%$ in MVPA). Again, one way ANOVA and post hoc analyses revealed large variability between schools $\left(F_{(1,121)}=4.06, p=0.002\right)$.

A greater proportion of variance was explained at the school-level for lesson time $(I C C=32.12)$ compared to break $(I C C=0.00)$, and lunch $(I C C=7.92)($ Table 2$)$. No individual- or school-level correlates predicted MVPA accumulation during lesson time. At break and lunchtime, gender and maturity offset predicted MVPA accumulation with gender-level effects at least two times greater than any other effect. Segment length was the only school-level correlate to predict an increase in MVPA at break. 
Table 2. Multi-level associations between pupil- and school-level predictors and moderate-to-vigorous physical activity across school segments.

\begin{tabular}{|c|c|c|c|c|c|c|c|c|c|}
\hline & \multicolumn{3}{|c|}{ Lesson Time } & \multicolumn{3}{|c|}{ Morning Break } & \multicolumn{3}{|c|}{ Lunchtime Break } \\
\hline & $b(\mathrm{SE})$ & $p$ & $95 \% \mathrm{CI}$ & $b$ (SE) & $p$ & $95 \% \mathrm{CI}$ & $b(\mathrm{SE})$ & $p$ & $95 \% \mathrm{CI}$ \\
\hline Constant & $\begin{array}{l}-12.83 \\
(16.30)\end{array}$ & 0.433 & $\begin{array}{c}-45.12 \text { to } \\
19.46\end{array}$ & $2.93(1.86)$ & 0.123 & -0.83 to 6.69 & $16.14(7.18)$ & 0.04 & 0.88 to 31.39 \\
\hline \multicolumn{10}{|c|}{ Pupil level variables } \\
\hline Gender (ref boys) & $-1.27(1.12)$ & 0.259 & -3.50 to 0.95 & $-2.85(0.55)$ & $<0.0005$ & -3.94 to -1.76 & $-6.09(1.37)$ & $<0.0005$ & $\begin{array}{c}-8.80 \text { to } \\
-3.37\end{array}$ \\
\hline Maturity offset & $1.18(0.88)$ & 0.182 & -0.56 to 2.92 & $0.89(0.43)$ & 0.039 & 0.05 to 1.73 & $2.53(1.06)$ & 0.019 & 0.43 to 4.64 \\
\hline BMI z-score & $0.05(0.27)$ & 0.838 & -0.48 to 0.59 & $-0.09(0.13)$ & 0.521 & -0.35 to 0.18 & $-0.44(0.33)$ & 0.183 & -1.10 to 0.21 \\
\hline \multicolumn{10}{|l|}{$\begin{array}{c}\text { School level } \\
\text { variables }\end{array}$} \\
\hline \multirow{3}{*}{$\begin{array}{c}\text { FSM }(\%) \\
\text { Segment length } \\
\text { Pupil level } \\
\text { variance }\end{array}$} & $0.04(0.10)$ & 0.682 & -0.20 to 0.29 & $-0.02(0.02)$ & 0.329 & -0.06 to 0.02 & $0.01(0.07)$ & 0.878 & -0.16 to 0.19 \\
\hline & $0.08(0.05)$ & 0.123 & -0.02 to 0.18 & $0.39(0.06)$ & $<0.0005$ & 0.24 to 0.54 & $0.14(0.10)$ & 0.195 & -0.09 to 0.38 \\
\hline & $10.04(1.32)$ & & & $2.45(0.32)$ & & & $15.24(2.00)$ & & \\
\hline $\begin{array}{c}\text { School level } \\
\text { variance }\end{array}$ & $4.75(3.01)$ & & & $0.00(0.08)$ & & & $1.32(1.24)$ & & \\
\hline ICC & 32.12 & & & 0.00 & & & 7.92 & & \\
\hline
\end{tabular}

FSM: free school meals; ICC: intraclass correlation; BMI z-score: body mass index standard deviation scores while accounting for normal growth by age and gender; SE: standard error; Bold: identifies significance $(p<0.05)$.

\subsection{Individual Lesson MVPA Profiles}

All lessons were relatively inactive, with only $2 \%, 2 \%$ and $4 \%$ of the available time spent in MVPA in lessons one, two and three, respectively. Pupils accumulated significantly more minutes of MVPA in lesson three $(4.65 \pm 2.86, p<0.0005$; range $1.90 \pm 0.95$ to $7.62 \pm 2.54 \mathrm{~min})$ compared to lessons one ( $1.75 \pm 1.56$; range $0.58 \pm 4.33$ to $2.71 \pm 2.08 \mathrm{~min})$ and two (1.41 \pm 0.93 ; range $1.01 \pm 0.59$ to $2.64 \pm 0.82 \mathrm{~min})$. A greater proportion of variance existed at the school level during lesson three $(I C C=49.81)$ compared to lesson one $(I C C=9.18)$ and two $(I C C=9.38$; Table 3). Segment length predicted time spent in MVPA during lessons one and two, but not lesson three. For every additional minute spent in lessons one and two, $0.04 \mathrm{~min}$ and $0.03 \mathrm{~min}$ of MVPA were accumulated, respectively, this effect was small. No individual level correlates predicted time spent in MVPA within any lesson.

Table 3. Multi-level associations between pupil- and school-level predictors and moderate-to-vigorous physical activity across academic lessons.

\begin{tabular}{|c|c|c|c|c|c|c|c|c|}
\hline & \multicolumn{2}{|c|}{ Lesson 1 (Start to Break) } & \multicolumn{3}{|c|}{ Lesson 2 (Break to Lunch) } & \multicolumn{3}{|c|}{ Lesson 3 (Lunch to Finish) } \\
\hline & $b(\mathrm{SE})$ & $p \quad 95 \% \mathrm{CI}$ & $b(\mathrm{SE})$ & $p$ & $95 \% \mathrm{CI}$ & $b(\mathrm{SE})$ & $p$ & $95 \% \mathrm{CI}$ \\
\hline Constant & $-2.57(2.27)$ & $0.271-7.28$ to 2.14 & $-0.36(1.16)$ & 0.756 & -2.72 to 1.99 & $2.98(13.88)$ & 0.831 & $\begin{array}{l}-24.97 \text { to } \\
30.94\end{array}$ \\
\hline \multicolumn{9}{|c|}{ Pupil level variables } \\
\hline Gender (ref boys) & $-0.01(0.48)$ & $0.977-0.97$ to 0.93 & $0.32(0.27)$ & 0.240 & -0.85 to 0.21 & $-1.05(0.71)$ & 0.142 & -2.46 to 0.36 \\
\hline Maturity offset & $0.11(0.37)$ & $0.776-0.63$ to 0.84 & $0.19(0.21)$ & 0.370 & -0.23 to 0.60 & $1.05(0.55)$ & 0.061 & -0.05 to 2.14 \\
\hline BMI z-score & $0.15(0.12)$ & 0.1930 .08 to 0.38 & $0.05(0.06)$ & 0.484 & -0.08 to 0.17 & $-0.13(0.17)$ & 0.448 & -0.47 to 0.21 \\
\hline \multicolumn{9}{|l|}{$\begin{array}{c}\text { School level } \\
\text { variables }\end{array}$} \\
\hline FSM $(\%)$ & $0.01(0.02)$ & $0.618-0.05$ to 0.07 & $0.00(0.01)$ & 0.807 & -0.03 to 0.04 & $0.04(0.09)$ & 0.662 & -0.19 to 0.27 \\
\hline Segment length & $0.04(0.01)$ & 0.0260 .01 to 0.07 & $0.03(0.01)$ & 0.007 & 0.01 to 0.06 & $0.04(0.11)$ & 0.720 & -0.18 to 0.26 \\
\hline $\begin{array}{l}\text { Pupil level } \\
\text { variance }\end{array}$ & $1.88(0.25)$ & & $0.58(0.08)$ & & & $4.00(0.53)$ & & \\
\hline $\begin{array}{l}\text { School level } \\
\text { variance }\end{array}$ & $0.19(0.17)$ & & $0.06(0.05)$ & & & $3.97(2.70)$ & & \\
\hline ICC & 9.18 & & 9.38 & & & 49.81 & & \\
\hline
\end{tabular}

FSM: Free School meals; ICC: Intraclass correlation; BMI z-score: body mass index standard deviation scores while accounting for normal growth by age and gender; SE: standard error; Bold: identifies significance $(p<0.05)$. 


\subsection{Individual Lessons and Subject Frequency}

The frequency of subjects across all schools was totalled by lesson period (Figure 2). Maths and English were the most frequently delivered subjects, totalling 36 and 44 occurrences respectively. This equates to seven sessions of maths and nine sessions of English, per school, per week, on average. Maths (43\%) and English (44\%) were the most frequently delivered sessions in lesson one ( $87 \%$ of all observations). Assembly was the only other subject to appear in lesson one (13\% of occurrences). In lesson two, once again, maths (38\%) and English (52\%) appeared with the greatest frequency, totalling $90 \%$ of all observations. History (3.3\%), science (3.3\%) and PSHE (3.3\%) each occurred once. During lesson three, all subjects were included (maths, English, science, computing, art and design, design and technology, geography, history, languages, music, PE, PSHE, topic, assembly and golden time); with English and PE occurring most frequently.
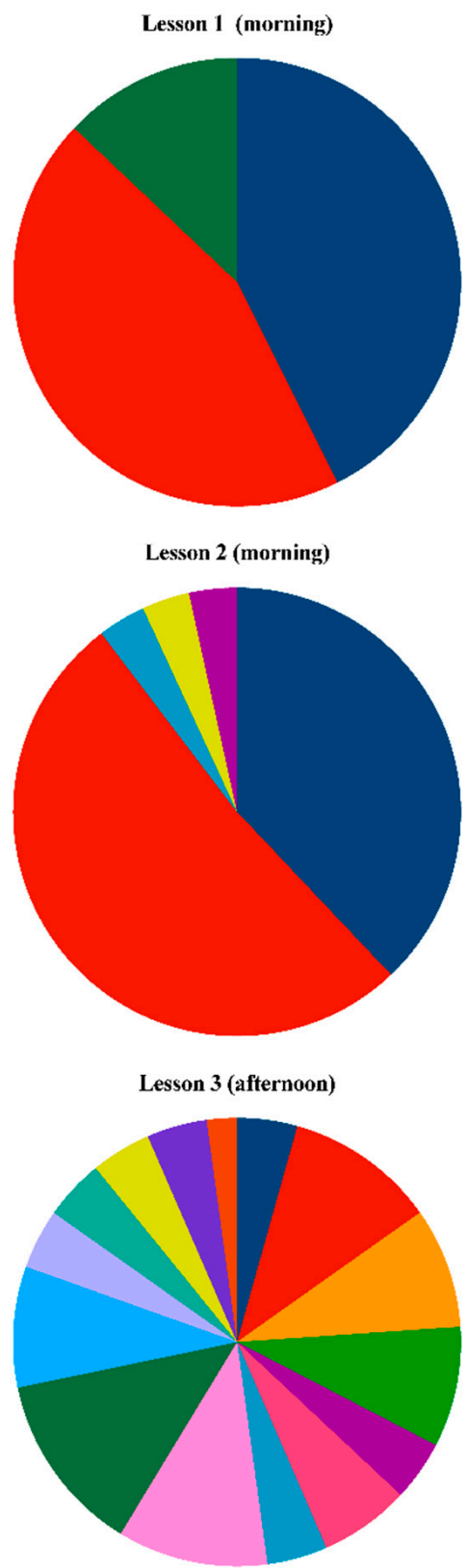

naths

- English

$\because \mathrm{Arl} / \mathrm{DT}$

- Computing

a RE

@ Geography

ascience

- $\mathrm{PE}$

- Assembly

- Topic

Language

- Golden time

DSIIE

- Music

n History

Figure 2. Total frequency of school subjects by lesson segment. (DT: design technology, PE: physical education, PSHE: personal, social, health and economic education, RE: religious education.). 


\section{Discussion}

This study advances current knowledge by presenting a detailed understanding of MVPA accumulation and subject frequency during academic lessons and across the school day. Extending the evidence base, school-level variability in MVPA accumulation was three times higher for academic lessons, than at break and lunchtime. Uniquely, we demonstrated the heterogeneous nature of academic lesson segments, with a greater school-level effect for lesson three (afternoon), compared to lessons one and two (morning). In lessons one and two, both dominated by maths and English, levels of MVPA were low. In lesson three (pm), while MVPA levels were higher and a greater variation in subjects were delivered, still only $4 \%$ of time was spent in MVPA. Consistent with the previous literature [23], gender, BMI z-scores and maturity offset did not predict lesson time MVPA.

In-school MVPA was $18 \mathrm{~min}$, aligning with the lower end of the range (16 to $61 \mathrm{~min}$ ) presented in a recent systematic review [14], and below that (24.8 $\mathrm{min}$ ) observed within a more recent meta-analysis using Evenson cut points [15]. Even though average levels of MVPA were lower than in previous studies, consistent with the previous literature, $90 \%$ of children in this study failed to accumulate 30-min of in-school physical activity per day [14]. Providing a more detailed understanding of in-school physical activity accumulation, $65 \%$ of children in this study accumulated less than $20 \mathrm{~min}$ of MVPA, with $12 \%$ accumulating less than $10 \mathrm{~min}$. These novel insights suggest that only substantial whole-school improvements in physical activity will deliver the policy-based recommendations of 30-min of in-school MVPA per day.

In agreement with previous studies $[23,25,26]$, pupils accumulated their lowest amount of MVPA during compulsory academic lesson segments, whereas discretionary periods, such as break and lunch, returned the most MVPA. In agreement with Fairclough et al. [23], ICCs from multilevel models revealed a $\sim 24 \%$ greater school-level variance in MVPA accumulation during academic lessons, compared to break and lunch. This finding suggests that classroom teachers and, potentially, other classroom or school-level factors are highly influential in determining the amount of MVPA accumulated during lesson time. When separating out the different lessons, the school-level effect reduced considerably for lessons one and two, yet remained high for lesson three. It is plausible that such low school-level variance in lessons one and two was due to the dominance of sedentary teaching and learning approaches for maths and English. Yet, in the afternoons, lessons included a wide variety of subjects, some of which potentially aligned to more active teaching and learning methods. Just as all schools delivered maths and English in morning lessons, PE was always an afternoon lesson. This likely explains a large proportion of the MVPA accumulated during this time segment. Yet, it is important to note that MVPA levels were still low in afternoon lessons, especially as the segment included PE lessons. Therefore, it should be emphasised that all lesson segments are ripe for the increased integration of MVPA and more active approaches to teaching.

Previous systematic reviews and meta-analyses justify the need to integrate more physical activity within the delivery of academic subjects through PAL or CMB [29-33]. Specific insights generated in the present study, especially regarding the different academic lesson segments and subjects therein, will enhance future intervention design and implementation. The dedicated focus on maths and English in morning lessons, where the least MVPA was accumulated, suggests that intervention developers should primarily focus on these segments and subjects. This finding presents a paradox, as maths performance is shown to improve with physical activity, yet this was the least active part of the school day $[20,51]$.

The present study adds more evidence to justify initial teacher training (ITT) providers integrating PAL within their courses $[52,53]$. The results from this study suggest building teachers' initial capability and motivation to integrate more movement in high-frequency core-subjects may have greater potential to increase MVPA than a broad focus on all subjects. Having said this, ITT or qualified teacher training programs may encourage teachers to reflect on the teaching strategies they deploy within the broader curriculum areas as these 
appear to promote more physical activity. Further, to enhance teachers' capability and motivation, schools also need to create opportunities for PAL. As seen in previous studies, schools should encourage using school gymnasiums and outdoor learning, while also providing physical resources to support the delivery of these lessons [7,54].

At a policy level, the study raises the need for a more holistic approach to education, where the physical and mental wellbeing of pupils is equal to their academic achievement. While the results are cross-sectional and limited to six schools in the North East of England, they provide insights into the current education landscape and the dominance of using sedentary approaches to teach core curriculum subjects. To move forward, further studies are required to confirm the results. Yet, when our results are shared at education conferences, the dominance of maths and English across morning lesson segments has not surprised audiences, providing further confirmation of their accuracy and relevance. As suggested within the Creating Active Schools Framework [7], this points to a need for national agencies responsible for health and education to align policies to promote the integration of health and well-being in the curriculum. Scandinavian countries, who lead the international field in this regard, have school environments that promote greater levels of physical activity than in those countries where this is not the case $[55,56]$. For example, in Denmark, schools are expected to provide 45-min of MVPA [57]. In Finland, the national "Schools on the Move" programme is funded by the Ministry of Education and Culture and organised by the Board of Education and regional state administrative agencies [58]. Both examples clearly demonstrate the national priority of physical activity in schools and the move to integrate movement within classroom lessons. Other countries are following suit, for example, the UK recommends "active lessons" within the latest PE and School Sport Premium Guidance [59]. To support schools, Daly-Smith et al. [52] provide a summary of the future directions for PAL implementation for policy, practice and research. The authors highlight the need for all three stakeholders to align to ensure all factors within the school-system facilitate PAL adoption and implementation.

\section{Strengths and Limitations}

Multi-level models represent an important methodological innovation for addressing variability in outcomes with multi-site interventions, accounting for the clustering of pupils within schools. Yet, due to the smaller numbers of individuals (level-one) within a few schools (level-two), the results should be interpreted with caution; fewer than 20 units at level two may introduce bias [60]. However, a strength of the current study lies in using this innovative analysis to reveal the pattern of MVPA and subject frequency in academic lessons. It should be noted that while the sample size may be small, it may not be feasible to conduct exploratory analyses in larger datasets. Further, the MVPA and ICC outcomes agree with the previous literature $[23,26]$, supporting the generalizability of the findings. However, for confirmation, large-scale studies should replicate the method with increased numbers of level one and two units. When comparing the results to the other literature, researchers should account for the methodology, specific geographical and socio-economic context and that data were collected in winter, when MVPA levels are typically lower than in the spring and summer $[6,61]$.

While physical activity was collected using accelerometers, uni-axial count-based data was used for the analysis. Future studies may choose to use triaxial accelerometers and adopt raw accelerations for their analysis [62]. While the teacher diaries have provided novel insights into the lesson pattern and frequency of curricular subjects, more objective methods of data collection may provide more accurate insights and may wish to be adopted in future studies. Further, capturing the delivery timings of the individual subjects would have enabled the data for Physical Education to be extracted from the afternoon lesson segment. Due to the usually high levels of MVPA in PE [63], it is likely that these lessons were at least partly responsible for the higher levels of MVPA in lesson three. While undertaking this analysis would not drastically alter the message that all lessons, especially 
morning lessons, are inactive and ripe for intervention, future large-scale studies should look to address this limitation.

\section{Conclusions}

In summary, to our knowledge, this study is the first to reveal the wide variation in MVPA accumulation and subject frequency across primary school academic lessons. Morning lessons were dominated by sedentary maths and English, whereas afternoon lessons featured a greater array of subject delivery that resulted in marginally higher levels of MVPA. These novel insights strongly suggest that all lessons segments are largely inactive, with the greatest opportunity to expand in-school MVPA occurring within morning lessons, dominated by maths and English. The findings further emphasise the urgent need to integrate physical activity within all lessons, especially maths and English. To facilitate this, future lesson-based interventions may wish to use the Creating Active Schools Framework to operationalise the multiple factors required for a whole-school approach to PAL; these include school policy, physical and social environments and all five stakeholder groups. Further, to support schools to implement more physical activity in academic lessons, national policy may need to rebalance pupils' academic achievement with their physical and mental well-being.

Author Contributions: A.D.-S., J.L.M. and M.A.D. created the study concept. A.D.-S. and M.A.D. led the design of the study with all authors contributing to the study design and ethics submission. A.D.-S. and J.L.M. recruited study participants and led data collection. All authors contributed to the data analysis. A.D.-S. drafted the manuscript and had the overall responsibility for the final content. All authors contributed to sections of the draft manuscript and have read, edited and agreed the published version of the manuscript. All authors have read and agreed to the published version of the manuscript.

Funding: This research was funded by Redcar and Cleveland Borough Council.

Institutional Review Board Statement: The study was conducted according to the guidelines of the Declaration of Helsinki, and approved by the Ethics Committee of Leeds Beckett University (37482, $8 / 5 / 2017)$.

Informed Consent Statement: Informed consent was obtained from all subjects involved in the study.

Data Availability Statement: The data are not publicly available as data sharing was not included within the original study ethics submission or participant consent form.

Conflicts of Interest: The authors declare no conflict of interest. The funders had no role in the design of the study; in the collection, analyses, or interpretation of data; in the writing of the manuscript, or in the decision to publish the results.

\section{References}

1. Tremblay, M.S.; Carson, V.; Chaput, J.-P.; Gorber, S.C.; Dinh, T.; Duggan, M.; Faulkner, G.; Gray, C.E.; Gruber, R.; Janson, K.; et al. Canadian 24-Hour Movement Guidelines for Children and Youth: An Integration of Physical Activity, Sedentary Behaviour, and Sleep. Appl. Physiol. Nutr. Metab. 2016, 41, S311-S327. [CrossRef] [PubMed]

2. World Health Organisation. WHO Guidelines on Physical Activity and Sedentary Behaviour; World Health Organization: Geneva, Switzerland, 2020.

3. Inchley, J.; Currie, D.; Budisavljevic, S.; Torsheim, T.; Jastad, A.; Cosma, A.; Kelly, C.; Mar, A.A.; Samdal, O. Spotlight on Adolescent Health and Well-Being. Findings from the 2017/2018 Health Behaviour in School-Aged Children (HBSC) Survey in Europe and Canada. International Report. Volume 2. Key Data; World Health Organisation: Copenhagen, Denmark, 2020; Volume 2.

4. Steene-Johannessen, J.; Hansen, B.H.; Dalene, K.E.; Kolle, E.; Northstone, K.; Møller, N.C.; Grøntved, A.; Wedderkopp, N.; Kriemler, S.; Page, A.S.; et al. Variations in accelerometry measured physical activity and sedentary time across EuropeHarmonized analyses of 47,497 children and adolescents. Int. J. Behav. Nutr. Phys. Act. 2020, 17, 38. [CrossRef] [PubMed]

5. Cooper, A.R.; Goodman, A.; Page, A.S.; Sherar, L.B.; Esliger, D.W.; Van Sluijs, E.M.F.; Andersen, L.B.; Anderssen, S.; Cardon, G.; Davey, R.; et al. Objectively measured physical activity and sedentary time in youth: The International children's accelerometry database (ICAD). Int. J. Behav. Nutr. Phys. Act. 2015, 12, 113. [CrossRef] [PubMed]

6. Sera, F.; Griffiths, L.J.; Dezateux, C.; Geraci, M.; Borja, M.C. Using functional data analysis to understand daily activity levels and patterns in primary school-aged children: Cross-sectional analysis of a UK-wide study. PLoS ONE 2017, 12, e0187677. [CrossRef] 
7. Daly-Smith, A.; Quarmby, T.; Archbold, V.S.J.; Corrigan, N.; Wilson, D.; Resaland, G.K.; Bartholomew, J.B.; Singh, A.; Tjomsland, H.E.; Sherar, L.B.; et al. Using a multi-stakeholder experience-based design process to co-develop the Creating Active Schools Framework. Int. J. Behav. Nutr. Phys. Act. 2020, 17, 13. [CrossRef]

8. World Health Organization. Global Action Plan on Physical Activity 2018-2030: More Active People for a Healthier World; World Health Organization: Geneva, Switzerland, 2018.

9. International Society of Physical Activity and Health. ISPAH's Eight Investments That Work for Physical Activity. Available online: www.ISPAH.org/Resources (accessed on 7 December 2020).

10. Department of Health and Social Care. Childhood Obesity: A Plan For Action, Chapter-2; HM Government: London, UK, 2018.

11. Metcalf, B.; Henley, W.E.; Wilkin, T. Effectiveness of intervention on physical activity of children: Systematic review and meta-analysis of controlled trials with objectively measured outcomes (EarlyBird 54). BMJ 2012, 345, e5888. [CrossRef]

12. Love, R.; Adams, J.; Van Sluijs, E.M.F. Are school-based physical activity interventions effective and equitable? A meta-analysis of cluster randomized controlled trials with accelerometer-assessed activity. Obes. Rev. 2019, 20, 859-870. [CrossRef]

13. Piercy, K.L.; Dorn, J.M.; Fulton, J.E.; Janz, K.F.; Lee, S.M.; McKinnon, R.A.; Pate, R.R.; Pfeiffer, K.A.; Young, D.R.; Troiano, R.P.; et al. Opportunities for Public Health to Increase Physical Activity Among Youths. Am. J. Public Health 2015, 105, 421-426. [CrossRef]

14. Grao-Cruces, A.; Velázquez-Romero, M.J.; Rodriguez-Rodriguez, F.; Velásquez-Romero, M.J. Levels of Physical Activity during School Hours in Children and Adolescents: A Systematic Review. Int. J. Environ. Res. Public Health 2020, 17, 4773. [CrossRef]

15. Tassitano, R.M.; Weaver, R.G.; Tenório, M.C.M.; Brazendale, K.; Beets, M.W. Physical activity and sedentary time of youth in structured settings: A systematic review and meta-analysis. Int. J. Behav. Nutr. Phys. Act. 2020, 17, 160. [CrossRef]

16. Lubans, D.R.; Richards, J.; Hillman, C.; Faulkner, G.; Beauchamp, M.; Nilsson, M.; Kelly, P.; Smith, J.J.; Raine, L.; Biddle, S. Physical Activity for Cognitive and Mental Health in Youth: A Systematic Review of Mechanisms. Pediatrics 2016, 138, e20161642. [CrossRef] [PubMed]

17. Bailey, R.; Hillman, C.; Arent, S.; Petitpas, A. Physical Activity: An Underestimated Investment in Human Capital? J. Phys. Act. Health 2013, 10, 289-308. [CrossRef] [PubMed]

18. Tomporowski, P.D.; McCullick, B.; Pendleton, D.M.; Pesce, C. Exercise and children's cognition: The role of exercise characteristics and a place for metacognition. J. Sport Health Sci. 2015, 4, 47-55. [CrossRef]

19. Álvarez-Bueno, C.; Pesce, C.; Cavero-Redondo, I.; Sanchez-Lopez, M.; Martínez-Hortelano, J.A.; Martínez-Vizcaíno, V. The Effect of Physical Activity Interventions on Children's Cognition and Metacognition: A Systematic Review and Meta-Analysis. J. Am. Acad. Child Adolesc. Psychiatry 2017, 56, 729-738. [CrossRef]

20. Singh, A.S.; Saliasi, E.; Berg, V.V.D.; Uijtdewilligen, L.; De Groot, R.H.M.; Jolles, J.; Andersen, L.B.; Bailey, R.; Chang, Y.-K.; Diamond, A.; et al. Effects of physical activity interventions on cognitive and academic performance in children and adolescents: A novel combination of a systematic review and recommendations from an expert panel. Br. J. Sports Med. 2019, 53, 640-647. [CrossRef]

21. Bartholomew, J.B.; Jowers, E.M. Physically active academic lessons in elementary children. Prev. Med. 2011, 52, S51-S54. [CrossRef]

22. Bailey, D.P.; Fairclough, S.J.; Savory, L.A.; Denton, S.J.; Pang, D.; Deane, C.S.; Kerr, C.J. Accelerometry-assessed sedentary behaviour and physical activity levels during the segmented school day in 10-14-year-old children: The HAPPY study. Eur. J. Pediatr. 2012, 171, 1805-1813. [CrossRef]

23. Fairclough, S.; Beighle, A.; Erwin, H.; Ridgers, N.D. School day segmented physical activity patterns of high and low active children. BMC Public Health 2012, 12, 406. [CrossRef]

24. Jago, R.; Page, A.S.; Cooper, A.R. Friends and Physical Activity during the Transition from Primary to Secondary School. Med. Sci. Sports Exerc. 2012, 44, 111-117. [CrossRef]

25. Nettlefold, L.; McKay, H.A.; Warburton, D.E.R.; McGuire, K.A.; Bredin, S.S.D.; Naylor, P.J. The challenge of low physical activity during the school day: At recess, lunch and in physical education. Br. J. Sports Med. 2010, 45, 813-819. [CrossRef]

26. Taylor, S.; Curry, W.; Knowles, Z.R.; Noonan, R.J.; McGrane, B.; Fairclough, S. Predictors of Segmented School Day Physical Activity and Sedentary Time in Children from a Northwest England Low-Income Community. Int. J. Environ. Res. Public Health 2017, 14, 534. [CrossRef] [PubMed]

27. Ickes, M.J.; Erwin, H.; Beighle, A. Systematic Review of Recess Interventions to Increase Physical Activity. J. Phys. Act. Health 2013, 10, 910-926. [CrossRef] [PubMed]

28. Lonsdale, C.; Rosenkranz, R.R.; Peralta, L.R.; Bennie, A.; Fahey, P.; Lubans, D.R. A systematic review and meta-analysis of interventions designed to increase moderate-to-vigorous physical activity in school physical education lessons. Prev. Med. 2013, 56, 152-161. [CrossRef] [PubMed]

29. Norris, E.; Shelton, N.; Dunsmuir, S.; Duke-Williams, O.; Stamatakis, E. Physically active lessons as physical activity and educational interventions: A systematic review of methods and results. Prev. Med. 2015, 72, 116-125. [CrossRef] [PubMed]

30. Martin, R.; Murtagh, E.M. Effect of Active Lessons on Physical Activity, Academic, and Health Outcomes: A Systematic Review. Res. Q. Exerc. Sport 2017, 88, 149-168. [CrossRef]

31. Daly-Smith, A.J.; Zwolinsky, S.; McKenna, J.; Tomporowski, P.D.; DeFeyter, M.A.; Manley, A. Systematic review of acute physically active learning and classroom movement breaks on children's physical activity, cognition, academic performance and classroom behaviour: Understanding critical design features. BMJ Open Sport Exerc. Med. 2018, 4, e000341. [CrossRef] 
32. Watson, A.; Timperio, A.; Brown, H.; Best, K.; Hesketh, K.D. Effect of classroom-based physical activity interventions on academic and physical activity outcomes: A systematic review and meta-analysis. Int. J. Behav. Nutr. Phys. Act. 2017, 14, 114. [CrossRef]

33. Norris, E.; Van Steen, T.; Direito, A.; Stamatakis, E. Physically active lessons in schools and their impact on physical activity, educational, health and cognition outcomes: A systematic review and meta-analysis. Br. J. Sports Med. 2019, 54, 826-838. [CrossRef]

34. Mooses, K.; Mägi, K.; Riso, E.-M.; Kalma, M.; Kaasik, P.; Kull, M. Objectively measured sedentary behaviour and moderate and vigorous physical activity in different school subjects: A cross-sectional study. BMC Public Health 2017, 17, 108. [CrossRef]

35. Morris, J.L.; Daly-Smith, A.; DeFeyter, M.A.; McKenna, J.; Zwolinsky, S.; Lloyd, S.; Fothergill, M.; Graham, P.L. A PedometerBased Physically Active Learning Intervention: The Importance of Using Preintervention Physical Activity Categories to Assess Effectiveness. Pediatr. Exerc. Sci. 2019, 31,1-7. [CrossRef]

36. Kaminsky, L.A.; Ozemek, C. A comparison of the Actigraph GT1M and GT3X accelerometers under standardized and free-living conditions. Physiol. Meas. 2012, 33, 1869-1876. [CrossRef] [PubMed]

37. Robusto, K.M.; Trost, S.G. Comparison of three generations of ActiGraph ${ }^{\mathrm{TM}}$ activity monitors in children and adolescents. J. Sports Sci. 2012, 30, 1429-1435. [CrossRef] [PubMed]

38. Dössegger, A.; Ruch, N.; Jimmy, G.; Braun-Fahrländer, C.; Mäder, U.; Hänggi, J.; Hofmann, H.; Puder, J.J.; Kriemler, S.; BringolfIsler, B. Reactivity to Accelerometer Measurement of Children and Adolescents. Med. Sci. Sports Exerc. 2014, 46, 1140-1146. [CrossRef]

39. Banda, J.A.; Haydel, K.F.; Davila, T.; Desai, M.; Bryson, S.; Haskell, W.L.; Matheson, D.; Robinson, T.N. Effects of Varying Epoch Lengths, Wear Time Algorithms, and Activity Cut-Points on Estimates of Child Sedentary Behavior and Physical Activity from Accelerometer Data. PLoS ONE 2016, 11, e0150534. [CrossRef] [PubMed]

40. Migueles, J.H.; Cadenas-Sanchez, C.; Ekelund, U.; Nyström, C.D.; Mora-Gonzalez, J.; Löf, M.; Labayen, I.; Ruiz, J.R.; Ortega, F.B. Accelerometer Data Collection and Processing Criteria to Assess Physical Activity and Other Outcomes: A Systematic Review and Practical Considerations. Sports Med. 2017, 47, 1821-1845. [CrossRef] [PubMed]

41. Evenson, K.R.; Catellier, D.J.; Gill, K.; Ondrak, K.S.; McMurray, R.G. Calibration of two objective measures of physical activity for children. J. Sports Sci. 2008, 26, 1557-1565. [CrossRef]

42. Cain, K.L.; Sallis, J.F.; Conway, T.L.; Van Dyck, D.; Calhoon, L. Using Accelerometers in Youth Physical Activity Studies: A Review of Methods. J. Phys. Act. Health 2013, 10, 437-450. [CrossRef]

43. Mattocks, C.; Ness, A.; Leary, S.; Tilling, K.; Blair, S.N.; Shield, J.; Deere, K.; Saunders, J.; Kirkby, J.; Smith, G.D.; et al. Use of Accelerometers in a Large Field-Based Study of Children: Protocols, Design Issues, and Effects on Precision. J. Phys. Act. Health 2008, 5, S98-S111. [CrossRef]

44. Department for Education. The National Curriculum in England-Framework Document. 2013. Available online: https:/ / assets.publishing.service.gov.uk/government/uploads/system/uploads/attachment_data/file/381344/Master_ final_national_curriculum_28_Nov.pdf (accessed on 22 January 2021).

45. Ruiz, J.R.; Castro-Piñero, J.; España-Romero, V.; Artero, E.G.; Ortega, F.B.; Cuenca, M.M.; Jiménez-Pavón, D.; Chillón, P.; GirelaRejón, M.J.; Mora, J.; et al. Field-based fitness assessment in young people: The ALPHA health-related fitness test battery for children and adolescents. Br. J. Sports Med. 2011, 45, 518-524. Available online: https://pubmed.ncbi.nlm.nih.gov/20961915/ (accessed on 29 September 2020). [CrossRef]

46. Cole, T.J.; Freeman, J.V.; A Preece, M. Body mass index reference curves for the UK, 1990. Arch. Dis. Child. 1995, 73, 25-29. [CrossRef]

47. Moore, S.A.; A McKay, H.; Macdonald, H.; Nettlefold, L.; Baxter-Jones, A.D.G.; Cameron, N.; Brasher, P.M.A. Enhancing a Somatic Maturity Prediction Model. Med. Sci. Sports Exerc. 2015, 47, 1755-1764. [CrossRef] [PubMed]

48. Field, A. Discovering Statistics Using SPSS; Sage Publications: London, UK, 2009.

49. Heck, R.H.; Thomas, S.L.; Tabata, L.N. Multilevel and Longitudinal Modeling with IBM SPSS; Routledge: London, UK, 2013; ISBN 9781135074173.

50. Sterdt, E.; Liersch, S.; Walter, U. Correlates of physical activity of children and adolescents: A systematic review of reviews. Health Educ. J. 2013, 73, 72-89. [CrossRef]

51. Sneck, S.; Viholainen, H.; Syväoja, H.; Kankaapää, A.; Hakonen, H.; Poikkeus, A.-M.; Tammelin, T. Effects of school-based physical activity on mathematics performance in children: A systematic review. Int. J. Behav. Nutr. Phys. Act. 2019, 16, 109. [CrossRef] [PubMed]

52. Daly-Smith, A.; Quarmby, T.; Archbold, V.S.; Routen, A.C.; Morris, J.L.; Gammon, C.; Bartholomew, J.B.; Resaland, G.K.; Llewellyn, B.; Allman, R.; et al. Implementing physically active learning: Future directions for research, policy, and practice. J. Sport Health Sci. 2020, 9, 41-49. [CrossRef] [PubMed]

53. Lander, N.; Mazzoli, E.; Cassar, S.; Symington, N.; Salmon, J. Embedding Active Pedagogies within Pre-Service Teacher Education: Implementation Considerations and Recommendations. Children 2020, 7, 207. [CrossRef] [PubMed]

54. Marchant, E.; Todd, C.; Cooksey, R.; Dredge, S.; Jones, H.; Reynolds, D.; Stratton, G.; Dwyer, R.; Lyons, R.; Brophy, S. Curriculumbased outdoor learning for children aged 9-11: A qualitative analysis of pupils' and teachers' views. PLoS ONE 2019, 14, e0212242. [CrossRef]

55. Norwegian Ministry Of Health And Care Services. The Action Plan on Physical Activity 2005-2009. Working Together for Physical activity; Norwegian Ministry of Health and Care Services: Oslo, Norway, 2005. 
56. Pate, R.R.; Trilk, J.L.; Byun, W.; Wang, J. Policies to Increase Physical Activity in Children and Youth. J. Exerc. Sci. Fit. 2011, 9 , 1-14. [CrossRef]

57. Skovgaard, T. Physically Active Schools 2020: New Pathways and Possibilities. 2015. Available online: https://idrottsforum.org/ skovgaard150318/ (accessed on 7 December 2020).

58. McMullen, J.; Ní Chróinín, D.; Tammelin, T.; Pogorzelska, M.; van der Mars, H. International Approaches to Whole-of-School Physical Activity Promotion. Quest 2015, 67, 384-399. [CrossRef]

59. Department for Education PE and Sport Premium for Primary Schools. Available online: https://www.gov.uk/guidance/peand-sport-premium-for-primary-schools (accessed on 9 January 2021).

60. University of Bristol Sample sizes for multilevel models I Centre for Multilevel Modelling | University of Bristol. Available online: http:/ / www.bristol.ac.uk/cmm/learning/multilevel-models/samples.html (accessed on 19 March 2018).

61. Atkin, A.J.; Sharp, S.J.; Harrison, F.; Brage, S.; Van Sluijs, E.M. Seasonal Variation in Children's Physical Activity and Sedentary Time. Med. Sci. Sports Exerc. 2016, 48, 449-456. [CrossRef]

62. Rowlands, A.V.; Edwardson, C.L.; Davies, M.J.; Khunti, K.; Harrington, D.M.; Yates, T. Beyond Cut Points: Accelerometer Metrics that Capture the Physical Activity Profile. Med. Sci. Sports Exerc. 2018, 50, 1323-1332. [CrossRef]

63. Hollis, J.; Williams, A.; Sutherland, R.; Campbell, E.; Nathan, N.; Wolfenden, L.; Morgan, P.; Lubans, D.R.; Wiggers, J. A systematic review and meta-analysis of moderate-to-vigorous physical activity levels in elementary school physical education lessons. Prev. Med. 2016, 86, 34-54. [CrossRef] [PubMed] 